\title{
Collection - Desenvolvimento de um ArtBook utilizando recursos e ferramentas aplicadas ao Design de personagens
}

\author{
Collection - Development of an ArtBook using features and tools applied to Character \\ Design
}

ABREU, Bruno R.; Graduado; Faculdades Integradas de Bauru

br.abreu@hotmail.com

PEREIRA, Douglas D.; Doutorando; Unesp

dougdanielpereira@gmail.com

LANUTTI, Jamille N. L.; Doutoranda; Unesp

Jamille_lanutti@hotmail.com

AMANTINI, Suzy, N. S. R.; Profa. Dra., Faculdades Integradas de Bauru

design@fibbauru.br

\section{Resumo}

São diversas as áreas onde o design de personagens pode atuar como a indústria do entretenimento através do cinema, games e histórias em quadrinhos, muitas vezes a escassez ou até a falta de um material específico que aborde essa temática e que possa auxiliar esses profissionais acaba limitando todo esse potencial. O objetivo desse artigo foi gerar através de uma pesquisa, um conceito, a fim de desenvolver personagens e apresenta-los por meio de uma peça gráfica e ilustrada destacando todas as etapas que são utilizadas no desenvolvimento desses personagens, contendo conceitos, sketches, pintura digital e teoria, compilando todas essas informações em um Artbook, para que possam ser utilizadas como ferramenta por esses profissionais no Design de Personagens.

Palavras Chave: Design, Design de personagens, Concept Art, Pintura Digital.

\begin{abstract}
There are several areas where the design of characters can act as the entertainment industry through movies, games and comics, often the scarcity or even the lack of a specific material that addresses this issue and that can help these professionals ends up limiting potential. The objective of this article was to generate through a research, a concept, in order to develop characters and presents them through a graphic and illustrated piece highlighting all the steps that are used in the development of these characters, containing concepts, sketches, digital painting and theory, compiling all this information into an Artbook, so they can be used as a tool by these professionals in Character Design.
\end{abstract}

Keywords: Design, Character Design, Concept Art, Digital Painting.. 


\section{Introdução}

O Design de personagens vem ao longo dos anos apresentando uma grande importância na indústria do entretenimento através do concept art, pois é através dele que é possível o desenvolvimento e a realização de trabalhos até então impossíveis de serem realizados.

O Concept Art é uma forma de ilustração em que o principal objetivo é transmitir uma representação visual de um projeto, ideia ou disposição para uso em filmes, games, animação ou quadrinhos antes que ele seja colocado no produto final (WIKIPEDIA, 2012).

Takahashi e Andreo (2011) atentam para o fato de que, na abordagem do processo do design de personagem, existe o momento da criação e desenvolvimento iterativo do personagem que por se tratar de uma etapa, extremamente crítica, encontra-se inserida no domínio do concept art.

A escassez de material que aborda os processos de desenvolvimento de personagens e apresentem as etapas desse processo é muito grande, salientando que em âmbito nacional esse tipo de material é ainda mais difícil de ser encontrado.

Ter acesso a um material que auxilie designers e ilustradores nas fases inicias de projeto é de vital importância, pois muitas vezes esses profissionais encontram dificuldade nas fases inicias do processo de criação. Sendo assim desenvolver um material dessa natureza pode auxiliar futuros projetos, auxiliando e inspirando as pessoas que admiram o processo de desenvolvimento de personagens para histórias em quadrinhos, animação, cinema e games, utilizando de técnicas para o desenvolvimento de ideias no processo criativo.

Esse artigo tem como objetivo um estudo e desenvolvimento dessas etapas e ferramentas que podem ser utilizadas durantes o processo criativo. A qual foi registrado por meio de um Artbook, mostrando os processos de desenvolvimento de um personagem partindo do conceito até a arte finalização do mesmo, a apresentação em forma de um Artbook demonstra e descreve cada uma das etapas criativas, com intenção de demonstrar algumas possibilidades e ferramentas que possam ser utilizadas no desenvolvimento projetual em Design.

\section{REFERENCIAL TEÓRICO}

\subsection{Concept art}

Concept Art é uma das técnicas de ilustração na qual o objetivo principal é passar uma representação visual de um design.

O concept art, pode ser considerado como representações visuais que buscam a materialização de conceitos idealizados para a indústria de entretenimento (como filmes de animação, ação livre e jogos eletrônicos), de forma a auxiliar no desenvolvimento dos projetos, pois acelera e torna mais coesa a produção, tornando possível incorporar, alterar e interagir visualmente com as ideias propostas [...] (TAKAHASHI E ANDREO, 2011).

Essa é uma designação muito utilizada para se referir a todo desenho conceitual que é gerado antes da ideia final. Este processo se encontra no início de uma produção, quando a estrutura de um game ou filme estão estabelecidos, cada profissional tem sua tarefa, como criar elementos dessas produções de determinada cena ou momento.

FredericSt-Arnaud (2010 p.37), em depoimento dado à Zupi, conta que considera como o 
fator mais apreciativo do concept art o fato de não existirem regras ou um processo específico a ser seguido, contanto que expresse de forma bem sucedida o conceito. St. Arnaud enfatiza que um bom concept artist deve ter uma boa noção em desenho, com um bom senso de perspectiva e de cores, necessita ser criativo e dominar variadas habilidades técnicas.

Portanto o profissional que domina algumas ferramentas, o seu processo ganha vida, opções de criações e finalizações, obtendo resultado diferenciados e bem resolvidos.

\subsection{Construção de personagens}

Seegmiller (2008) afirma que mais do que apenas criar ou desenhar alguma coisa, o design de personagens tem o poder de trazer à tona as crenças, expectativas e reações do público quanto aos aspectos formais, compleição física e o caráter destes personagens.

O autor nos diz que não basta criar apenas, cada processo tem seu valor no desenvolvimento de um personagem, é além de uma imaginação, obedecendo regras para que sua criação tenha o sucesso desejado, sendo ele criado para ser o mocinho ou o vilão, e elementos de design como Gesture e Gestalt, podendo auxiliar a criar um bom personagem, como profissionais do ramo costumam dizer - "Se a silhueta vende, o trabalho está aprovado." Com isso podemos dizer que praticamente qualquer construção, elaboração de um personagem e a forma do mesmo contará muito, o shape contribuirá no carisma de seu trabalho.

Um fato a se ressaltar, segundo o autor, seria que o público está se tornando cada vez mais sofisticado com relação às expectativas visuais. Seegmiller (2008, p.04) cita o exemplo do monstro de Frankenstein, que costumava ser uma figura muito assustadora em tempos anteriores, hoje em dia, porém, é preciso figuras muito mais apelativas e complexas para gerar o mesmo impacto na audiência.

Com a tecnologia e a informação a nossa mão, o acesso ficou rápido e fácil, pesquisar assuntos aleatórios, assim para criar e elaborar personagens e com toda essa informação se perdem no processo criando apenas mais uma criatura. Seegmiller $(2008$, p.05), é uma tarefa difícil, isto porque cada pessoa é única, e o que é bom para um, pode não ser para outro.

\subsection{Desenho}

O Desenho é uma técnica, usada para expressar acontecimentos e registrar momentos. Lima (2010) diz que as técnicas de desenho e pinturas aplicadas nos dias de hoje são parecidas com as usadas antigamente, pois ainda hoje se usa a tradicional folha de papel e um lápis. Ter conhecimento, praticar e fazer uso do desenho são objetivos de vital importância para um designer ou artista, pois desenhar é uma das mais importantes habilidades desenvolvidas pelo homem e o seu estudo e o aprimoramento são imprescindíveis na formação de um profissional, uma vez que se espera que o mesmo consiga de forma rápida e confiável comunicar e até mesmo exemplificar uma ideia através do desenho (FENG ZHU ,2010).

Huante (2003) diz que o desenho é a coisa mais importante e que hoje em dia parece que por conta dos computadores, alguns artistas tornaram-se preguiçosos em relação ao desenho. Os computadores são excelentes ferramentas, mas não devem ser tudo. Para ele a prática e o estudo do desenho são fundamentais uma vez que só saber desenhar não quer dizer que você seja tão bom assim, e que computador nenhum pode fazer todo trabalho sozinho, assim como o lápis também não pode fazer tudo sozinho. $O$ desenho sempre estará presente, e os computadores aparecem como complemento para auxiliar o processo de criação, diante do exposto podemos dizer que a 
falta de disciplina é a real causa da falta de criação. Com a disseminação dos computadores buscamos atalho para o desenho, nos tornando preguiçosos e com a praticidade e versatilidade nos deixam acomodados, sempre buscando um meio mais rápido para finalizar um trabalho.

\subsection{Sketches}

Takahashi e Andreo (2011) afirmam que o estudo do Desenho está intimamente ligado ao sketch, que se traduzido para o português pode significar esboço, rascunho ou desenho sumário. Podendo ainda ser visto como um exercício muito importante para o treinamento do designer ou do artista, tanto na composição quanto no gestual do personagem ou imagem em questão. O uso do sketch para o designer é uma das etapas mais importantes, pois e o momento de rabiscar e esboçar toda ideia para que a mesma não se perca.

Sketching é a tão chamada prática que leva a perfeição. É o exercício mais importante para o desenho e acabará por se tornar arte com base em suas ideias criativas. [...] Sketching possibilita ao artista a habilidade de tomar decisões sobre suas ideias iniciais sem medo de estragá-las por causa de erros que demoram em se corrigir posteriormente. Quando se faz desenhos rápidos e simples de um assunto, $o$ artista na verdade permite mudanças na arte antes de se tornarem presas á ideias que acabam por se tornar difíceis de mudar por causa do tempo e esforço gasto neles". (LIPPINCOTT 2007 p.20).

Conforme citado o uso do sketch é uma vantagem rápida para tomada de decisões evitando gastos desnecessários, seja para o designer ou para toda equipe.

Já Lippincott (2007) afirma que os sketches permitem a consideração visual de poses alternativas para personagens, explorando também diferentes pontos de vista ou recortes da figura, possibilitando uma visão geral da composição, e por consequência, uma escolha mais segura da melhor alternativa para o refinamento do desenho, diminuindo o nível de frustração em projetos. Assim no design de os sketches colaboram com ideias rápidas de diferentes dimensões nos proporcionando uma idealização e nos mostrando onde cada elemento se posicionara, nos dando fluxo de trabalho deixando o processo linear, evitando possíveis bloqueios, e erros ao criar.

\subsection{Arte digital}

Arte digital se tornou um conceito para qualquer manifestação artística. Por definição, o trabalho artístico deve ter sido gerado de forma digital, o que pode ser descrito eletronicamente como séries de zero e um. Nem tudo criado de forma eletrônica é considerado arte. Ainda assim, as raízes da arte digital também podem ser encontradas na matemática e na computação. De forma geral, podemos dizer que arte digital é como projeto em que foi empregado o potencial do computador para sua criação.

Lima (2010) diz que todo conhecimento adquirido da arte tradicional pode ser aproveitado para a arte digital, pois os inúmeros fabricantes de softwares que simulam ferramentas tradicionais - de pintura ou escultura - tem tido a preocupação de aproximar seus programas com a forma como os artistas renomados trabalhavam quando existiam apenas o lápis, o pincel e as ferramentas de escultura. Isto tem favorecido a aparição cada vez mais de pessoas que se adaptam bem a esta nova forma de fazer arte. Quem já domina alguma ferramenta tradicional, certamente não terá problemas em se adaptar ao novo meio, uma vez que haja interesse e perseverança. 


\section{Objetivos}

O objetivo desse projeto foi gerar através de uma pesquisa, um conceito, a fim de desenvolver personagens e apresenta-los por meio de uma peça gráfica e ilustrada destacando todas as etapas que são utilizadas no desenvolvimento desses personagens, contendo conceitos, sketches, pintura digital e teoria, compilando todas essas informações em um Artbook, para que possam ser utilizadas como ferramenta no Design de Personagens.

\section{Materiais e métodos}

\subsection{Desenvolvimento da história}

Uma etapa importante do concep art é a elaboração de um enredo base, onde todo o projeto se desenvolverá auxiliando na criação e desenvolvimento de cenários, personagens, objetos, etc. Destaca que um enredo não se gera do nada, consulta, pesquisas e inspirações são necessárias para desenvolver um bom trabalho, além disso o concept artist tem sempre que se atualizar, nas indústrias de games, filmes e buscar conhecimentos e informações culturais que ajudam e auxiliem em seu repertorio.

Para este projeto destaca-se algumas referências (Figura 01) como os filmes A mosca (1987), Tusk a transformação (2014), artbooks como Dead Space (2011), The EvilWithin (2014), DOOM (2016) games como Residente Evil (2017), Dead Space (2011). Artistas como Dominic Qwek, Anthony Jones, Rafael Grassetti, Alex Oliver.

Figura 01 - Painel semântico referências

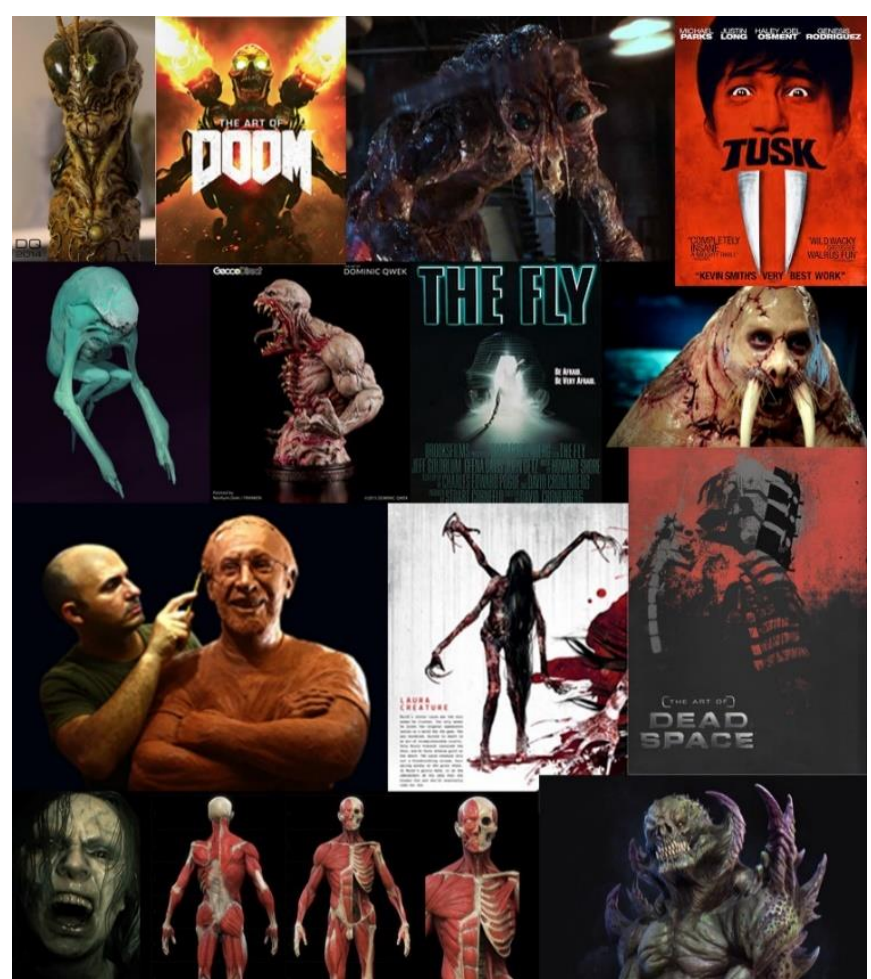

Fonte: Google Imagens 
Dessa forma, partindo das referências escolhidas e estabelecendo o caminho da história, até chegar aos tópicos que direcionam quem são os personagens e sua importância, obtendo identidade e personalidade.

\subsection{Enredo}

Desde pequeno Theodor tem suas dificuldades, comportamento estranho diferenciado de outras crianças, com um pai famoso na medicina para a época. Theodor cresceu em um meio de assuntos médicos, com poucos amigos e familiares, o contato com o mundo exterior era mínimo e seu fascínio por insetos era grande, suas vontades para um pequeno garoto assustavam, porém guardava um segredo. Theodor se torna Dr. em um futuro próximo agindo como um psicopata no silêncio, querendo colocar suas habilidades em prática, testes e experimentos ilegais, para saciar seu ego e avançar em suas pesquisas, gerando formas, criaturas e todo tipo de atrocidades.

\subsection{A história e aparência do personagem}

A elaboração de um personagem permite a combinação de vários elementos e características, dando the personalidade única e marcante. Uma das primeiras etapas, segundo Seegmiller , 2008 (apud TAKAHASHI E ANDREO, 2011) trata-se do momento que, no campo do design é chamado de briefing, o qual configura uma série de perguntas vitais para o projeto. Para o design de personagens, o autor propõe as seguintes perguntas,

- $\quad$ Como o personagem será usado?

- $\quad$ Como o personagem será exibido (mídia)?

- Qual o tamanho do personagem com relação aos outros?

- $\quad$ O personagem será animado? Como?

Esta etapa do briefing é uma parte fundamental do projeto, pois elas deverão estar sempre junto com o artista e direcionar várias decisões, a influência destas perguntas irá sempre aparecer na base estrutural do design.

Seegmiller , 2008 (apud TAKAHASHI E ANDREO, 2011) explana sobre algumas estratégias básicas que podem ajudar no desenvolvimento de ideias criativas:

- $\quad$ Respirar fundo e relaxar. Conversar consigo mesmo sobre o problema;

- $\quad$ Observar o que está à sua volta, deixar a mente vagar. Libertar a sua mente;

- Tentar ver o assunto sobre uma nova perspectiva.

A pesquisa de material de referência é fundamental, assim como saber utilizá-lo de forma apropriada. Seegmiller (2008), apresenta uma lista para ilustrar o conceito de combinar palavras para formar novas ideias para trabalhar. Naturalmente, essa lista não se destina a nenhum problema específico; as listas que você usaria devem ser personalizadas para o seu problema. Algumas combinações:

- Fantasiar sobre o personagem;

- Construir o personagem em torno de um mito;

- Fazer uso de Simbolismos com o Personagem;

- Visitar lugares especiais para inspiração; 
Outro fator de extrema importância para o projeto é a silhueta do personagem, que Raynes \& Raynes (2000, p.16) sugere ser uma das habilidades mais importantes que o concept artista precisa desenvolver, pois sem estabelecer uma forma inicial que apresente algumas particularidades do personagem, todo o restante pode ser rico em detalhes, porém sem uma estrutura o personagem não se sustenta.

Já a história do personagem auxiliará você, o designer, a realmente conhecer o que irá desenhar. Possuindo uma história para seu personagem ajudará a compreenderas pequenas questões que possibilitarão uma visão necessária para a criação de um design bem-sucedido. (SEEGMILLER, 2008, p.34)

Para Takahashi e Andreo (2011) a criação de uma história por trás do personagem possibilita uma personalidade mais complexa e evita a criação de personagens "rasos", ou seja, personagens ordinários e sem profundidade. A história é necessária mesmo que jamais seja revelada totalmente para o público e permaneça apenas na mente do designer.

Seegmiller , 2008 (apud TAKAHASHI E ANDREO, 2011) sugere que o primeiro passo seria imaginar o passado, presente e futuro do personagem. $O$ autor elabora algumas possíveis perguntas que podem ajudar no desenvolvimento da história do personagem:

- $\quad$ Qual a personalidade do personagem e como sua história influencia a mesma?

- Qual o nome do personagem?

- Qual a árvore genealógica do personagem?

- $\quad$ O personagem é baseado em alguma lenda ou mito?

- $\quad$ O público irá conhecer e entender sua origem?

Com alguns questionamentos e pensamentos apresentados nota-se que para a elaboração de um personagem fica claro a dedicação que o concept artist precisa ter em seu trabalho, todos os detalhes fazem uma grandiosa diferença para um desenvolvimento bem estruturado, sem dúvida, algo de crucial importância para o desenvolvimento de projetos voltados para a indústria do entretenimento.

\subsection{Personagem Dr. Theodor}

Para o desenvolvimento do personagem Dr. Theodor, foi utilizado um painel semântico (Figura 02) que norteou como seria a aparência do mesmo, a vestimenta e até o comportamento do personagem, pois apesar de criar criaturas bizarras, tem um visual moderno e alinhado, deixando com uma aparência amigável, porém por dentro não seja nada disso.

Dr. Theodor um médico expulso do comitê por realizar experiências aterrorizantes em seus pacientes, um olhar frio e sem sentimentos, com prazer em machucar as pessoas. 
Figura 02 - Painel de referências estrutura e roupas
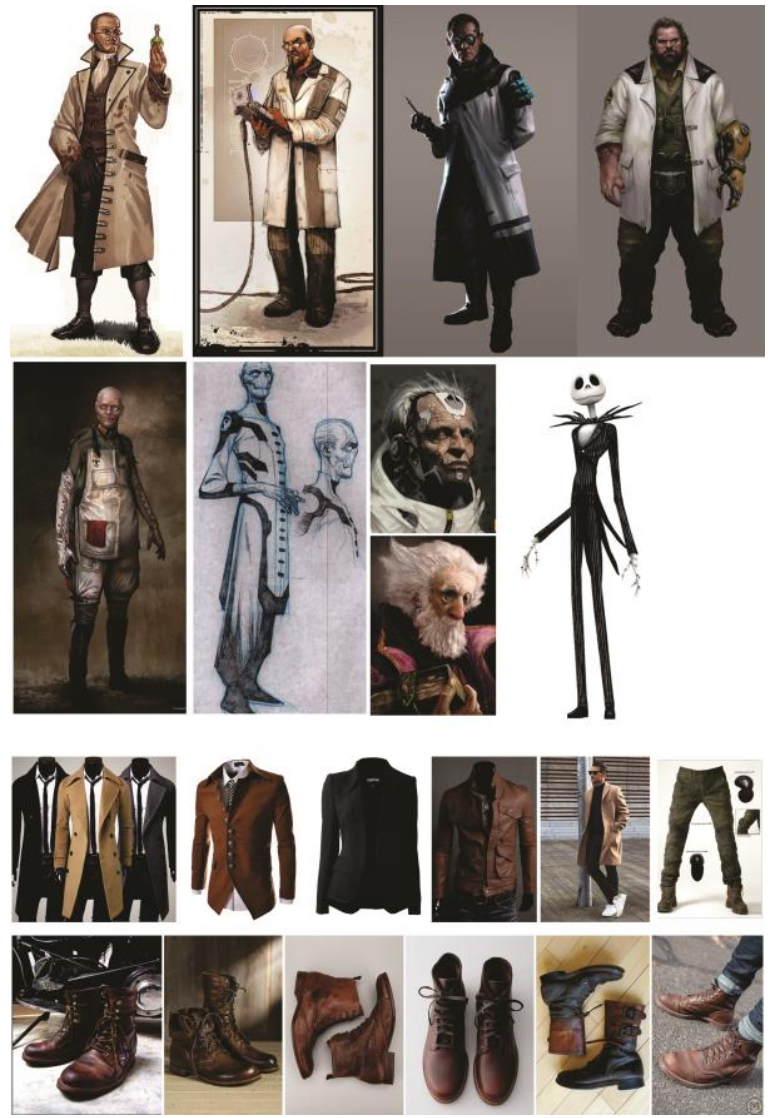

Fonte: Google imagens

\subsection{Painel semântico de conceito no desenvolvimento do personagem}

Pazmino (2015) diz que, a partir dos requisitos do projeto estabelecidos, ou da síntese do projeto no diagrama de Ishikawa, uma técnica interessante para visualizar as características que deverá ter o produto ou serviço são painéis semânticos do conceito do produto. Este painel, também conhecido como conceptboard, ajuda na definição e visualização do significado do produto para facilitar na geração de alternativas a criação do estilo do produto, definição dos aspectos semântico, simbólicos, etc. Uma técnica valiosa para criação, utilizada para desenvolver um dos personagens, acrescentando referências ao painel, como estilos, core e personalidade.

\subsection{Sketch}

Essa etapa de desenvolvimento, como dita nos tópicos anteriores, auxiliam o processo de trabalho, evitando futuros erros de projeto, a elaboração do primeiro personagem tem como ajuda o painel de conceito, as imagens já estabelecidas que será utilizado para essa etapa, o processo de sketch e o momento de dar a forma, idealizando, testando sem o medo do erro, como podemos ver na (Figura 03) a geração de algumas ideias como bigodes, casacos, faces e duas personalidades diferentes, mantendo o mesmo visual moderno, porém com a mesma essência de médico. 

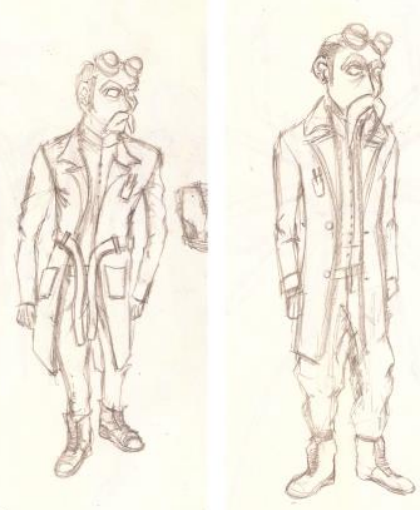

Figura 03 - Sketches Dr. Theodor personagem 1
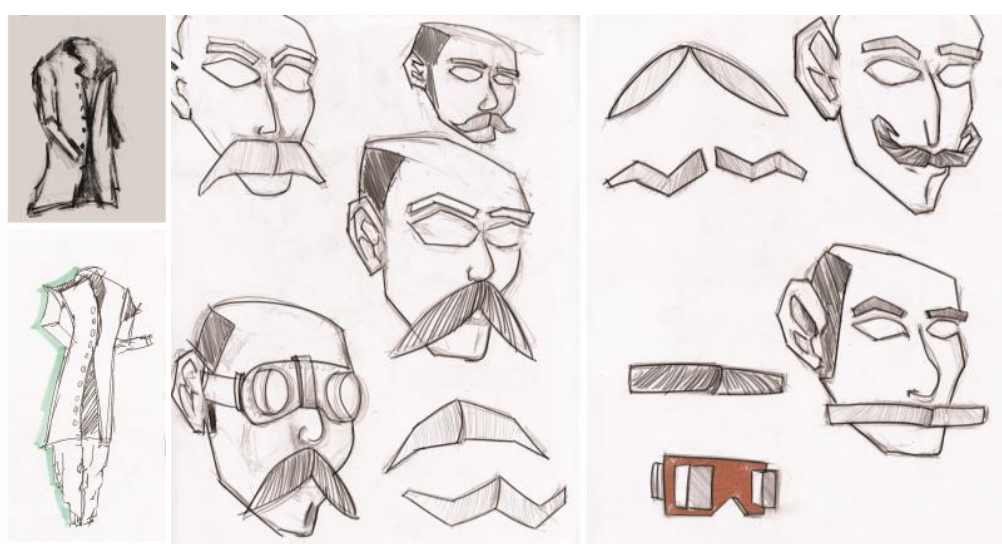

Fonte: Elaborada pelo autor

\subsection{Arte finalização}

$\mathrm{Na}$ (Figura 05) inicia se o processo de vetor, realizado no CorelDraw, um software de vetorização e colorização, deixando o processo refinado com linhas definidas, pronto para receber a cor, com o auxílio do painel de conceito, as cores foram estabelecidas e relacionadas com cada peça de roupa, sempre procurando gerar tons neutros, para que a aparência do doutor se mantenha moderna sem extravagancia. De acordo com o site Printi (2017), na psicologia das cores a cor cinza "Traduz elegância, velhice, tédio, respeito e até tristeza." Uma das cores que combinou com o estilo só personagem e seu significado.

Figura 04 - Vetor paleta de cor e finalização personagem 01
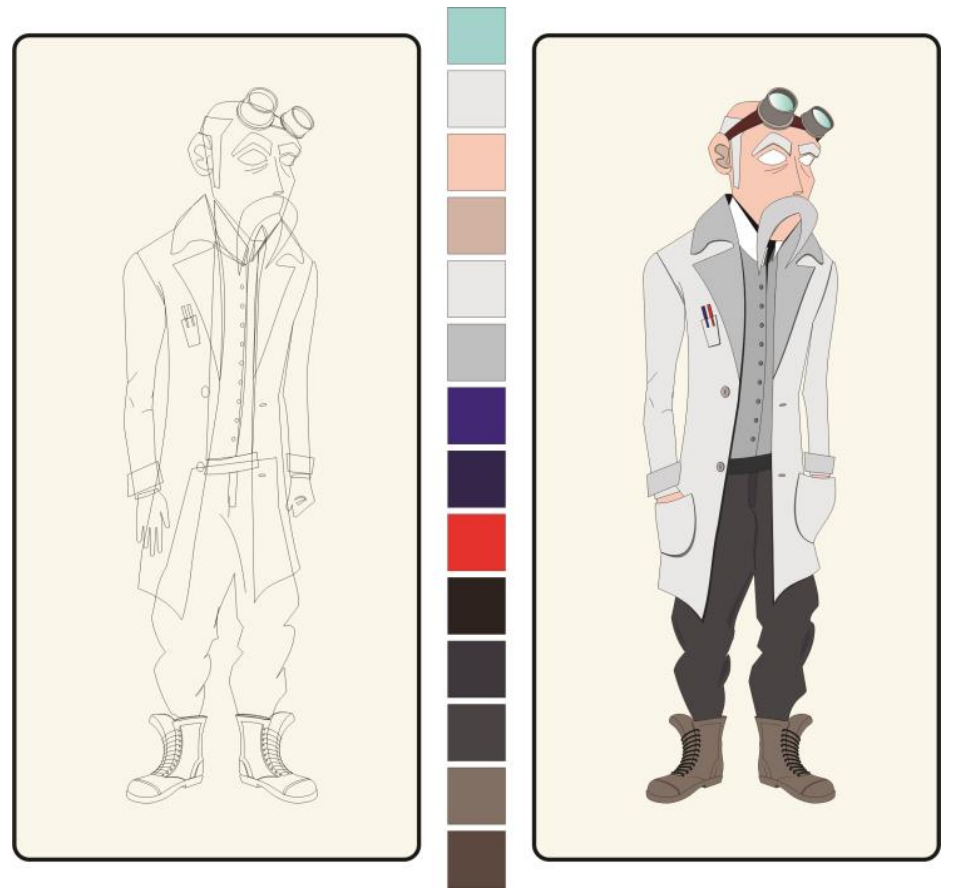

Fonte: Elaborada pelo autor 


\section{Confecção do Artbook}

Todos processos citados, foram reunidos em um Artbook, ilustrado com diagramação elaborada e mais de 10 páginas em um formato de $17 \times 24 \mathrm{~cm}$, um papel de gramatura $115 \mathrm{~g}$ proporcionando um papel mais maleável, contribuindo para arte final, o logotipo (Figura 05) a capa interna (Figura 06), o layout da página do artbook (Figura 07) e capa externa courino rústico, arte desenvolvida em software CorelDraw ${ }^{\circledR}$ com gravação a laser (Figura 08).

Figura 05 - Arte final

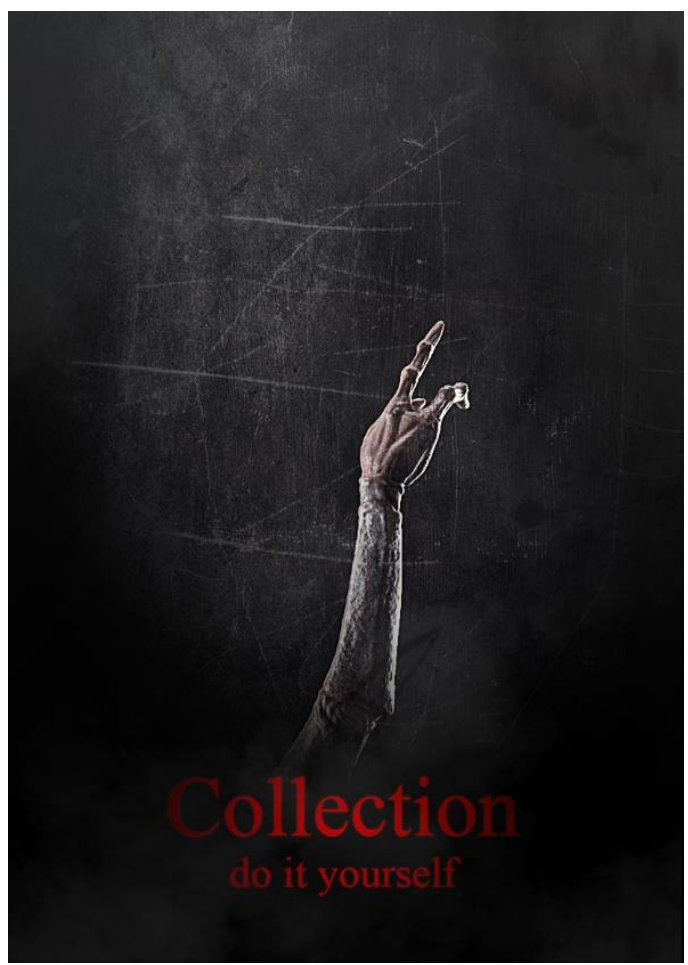

Fonte: Elaborado pelo autor

Figura 06 - identidade Visual do Artbook

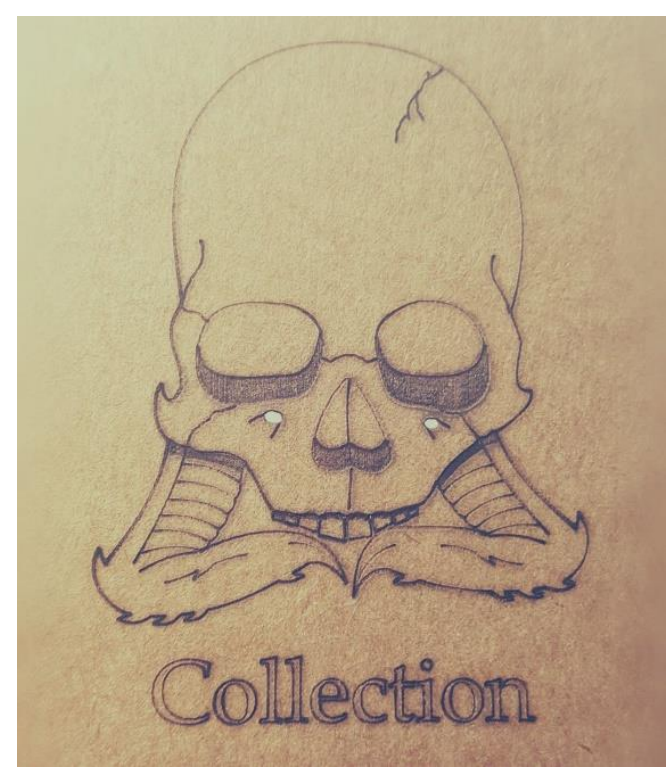

Fonte: Elaborado pelo autor 
Figura 07 - Layout das páginas do Artbook.

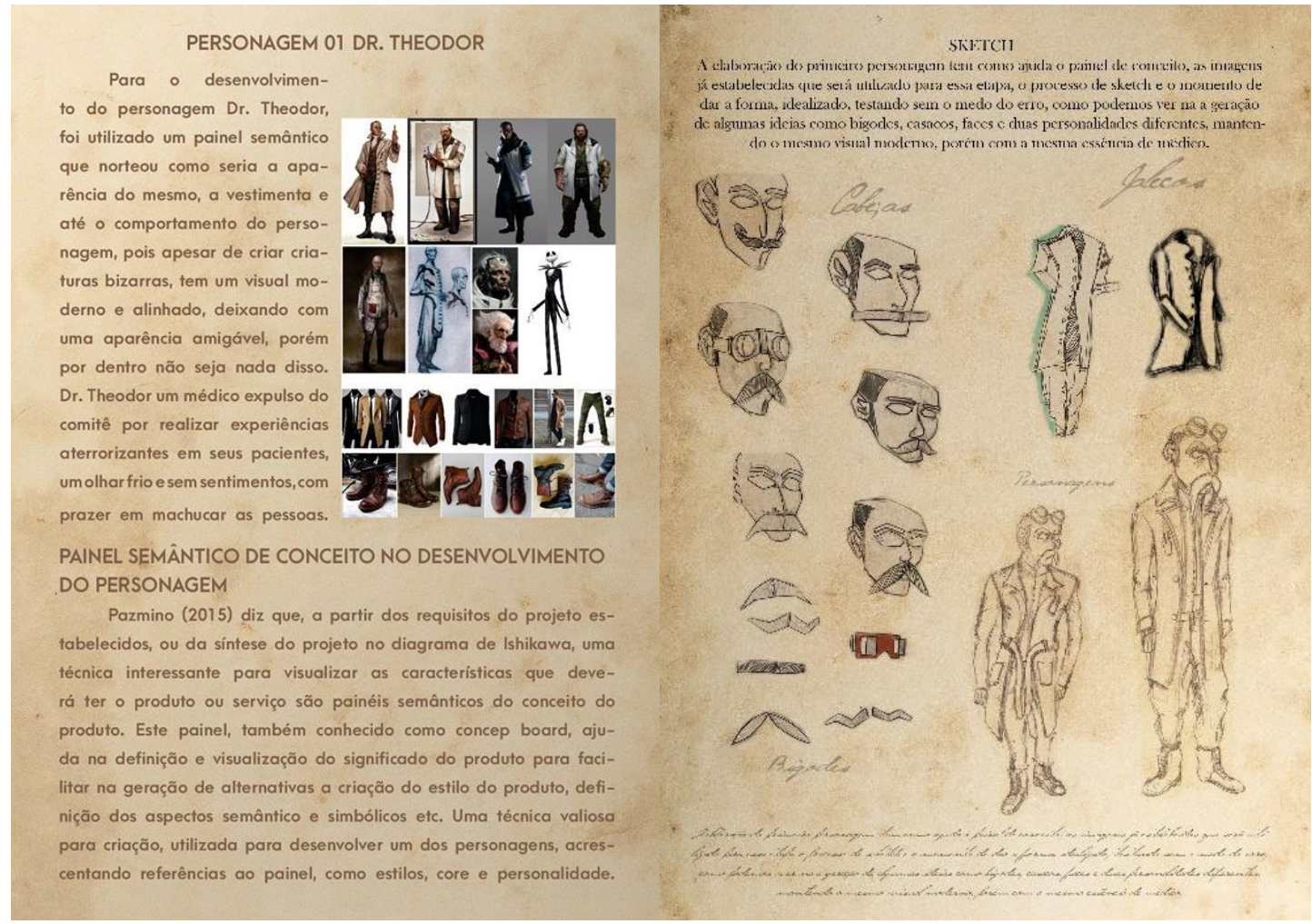

Fonte: Elaborado pelo autor

Figura 08 - Artbook final.

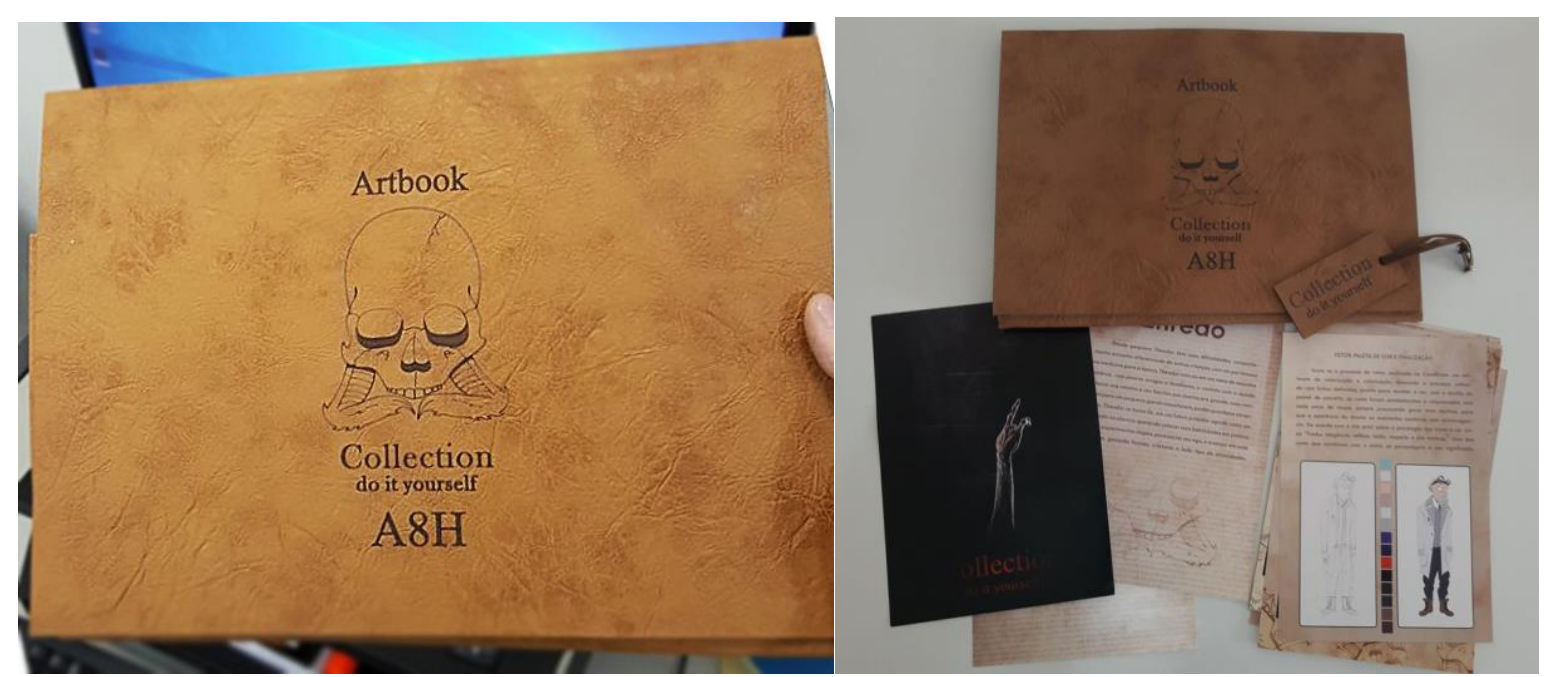

Fonte: Elaborado pelo autor 


\section{CONSIDERAÇÕES FINAIS}

Este artigo teve como objetivo o estudo do concept art no desenvolvimento de personagens em paralelo com design, o projeto apresentou desafios e mostrou que é possível através de um estudo mais apurado evoluir em todos os processos aqui aplicado, além do que desenvolver um projeto dessa natureza alcança não só uma realização pessoal, como também profissional uma vez que o uso das ferramentas apresentadas contribuiu de alguma forma.

Acredita-se que este trabalho expandiu os conhecimentos passando pelos processos de criação, como cada etapa tem sua importância e como cada um ajuda no processo seguinte, chegando no resultado final com clareza.

Ao decorrer do trabalho realizado pôde agregar conhecimento, que servirão para trabalhos futuros. Com essa área em expansão esse processo de trabalho abre um leque de novas possibilidades criativas para se ter um melhor resultado, assim um campo cheio de oportunidades de aprendizado e atuação de um designer.

Considera-se em ter colaborado mostrando um pouco do desenvolvimento de personagens agregado ao design e também, que os processos aqui usados servirão de apoio a futuros estudantes de design que tenham como foco o concept artistas, pois o que fica é um material de consulta e apoio a futuros trabalhos.

Conclui-se que o tempo investido na realização desse projeto acrescentou um olhar crítico, conhecimentos e técnicas mais apuradas, que o tempo e a paciência são aliados a qualquer projeto.

\section{Referências}

HUANTE, C. Monstruo The of Carlos Huante .Culver City, CA: Design Studio Press, 2004.

LIMA, A. P. Z Brush para Iniciantes. Rio de Janeiro: Ciência Moderna Ltda, 2010.

LIPPINCOTT, G. The Fantasy Illustrator's technique book. London: Barron's, 2007.

PAZMINO, A. V. Como se cria: 40 técnicas de criações. Blucher: Florianópolis. 2015.

PRICKEN, Mario. Publicidadcreativa. Barcelona: Gustavo Gili, 2009, matriz morfológica. Processo Criativo. 2013. Disponível em: <http://www.processocriativo.com/matriz-morfologica/>. Acesso em 15. Jul. 2017

PSICOLOGIA DAS CORES: você sabia que cada cor pode alterar sua percepção? Printi. 2013 Disponível em <https://www.printi.com.br/blog/psicologia-das-cores-voce-sabia-que-cada-corpode-alterar-sua-percepcao>. Acesso em 10. Jul. 2017

SEEGMILLER, D., 2008. Digital CharacterPaintingUsing Photoshop CS3. Boston: Charles River Media

TAKAHASHI, P. K.; ANDREO, M. C. Desenvolvimento de Concept Art para Personagens. In: SBC - Proceedings of SBGames 2011.

ZUPI, 2010. Concept Art Issue. São Paulo: Zupi, n. 01.

ZHU, F. FZD Schoolof Design. Disponível em: < http://www.fzdschool.com/>. Acessado em 1. Jul. 2017. 